\title{
PEMISAHAN BAHAN AKTIF DALAM BUAH SOSIS (Kigelia africana) DENGAN METODE EKSTRAKSI PADAT-CAIR (LEACHING)
}

\author{
Ahmad Fauzan ${ }^{1}$, Mukhtar Ghozali1 ${ }^{1, *}$, Tri Reksa Saputra ${ }^{1}$, Heni Khautsar \\ Muchtari $^{1}$, Maria Rosa Mistika Mopa ${ }^{1}$ \\ ${ }^{1}$ Jurusan Teknik Kimia, Politeknik Negeri Bandung, Indonesia \\ Jln. Gegerkalong Hilir, Ds. Ciwaruga, Bandung 40012 \\ *E-mail: muhtar_2008@yahoo.com
}

\begin{abstract}
ABSTRAK
Industri kosmetik dan farmasi merupakan contoh industri yang saat ini banyak menggunakan bahan alami sebagai bahan baku dalam pembuatan produknya. Salah satu tanaman herbal adalah buah sosis. Buah sosis mengandung senyawa-senyawa aktif penting bagi manusia, yaitu flavonoid, iridoid, naphthoquinone, dan coumarin. Tujuan dari penelitian ini adalah menentukan jenis pelarut, rasio pelarut/bahan baku, waktu operasi, dan persen yield terbaik dalam proses ekstraksi buah sosis dengan metode ekstraksi soxhlet pada variasi jenis pelarut (etanol $96 \%$ dan metanol), rasio volume pelarut/berat bahan baku (8:1, 10:1, 12:1), dan waktu operasi (1,2, dan 3 jam). Berdasarkan data yang diperoleh, ekstrak terbaik yaitu ekstrak yang menggunakan pelarut metanol, waktu ekstraksi selama 3 jam, dan rasio pelarut/bahan baku yaitu 10:1, dengan perolehan yield sebesar 33,12\%. Hasil uji kualitatif menunjukkan bahwa pada ekstrak tersebut mengandung empat senyawa yang diinginkan. Sementara hasil uji kuantitatif menunjukkan bahwa pada ekstrak metanol buah sosis tersebut terkandung flavonoid sebanyak 5168 ppm.
\end{abstract}

Kata kunci: Buah sosis, ektraksi, flavonoid, iridoid, naphthoquinone

\begin{abstract}
Cosmetic and pharmaceutical industry are two examples of some industries that currently uses a lot of chemical substances as the raw materials to produce their products. But there has been some research about natural substances to replace chemical substances as the raw materials. One of the natural substances is sausage fruit. Sausage fruit contains important bio active compounds for human life such as flavonoids, iridoids, naphthoquinones, and coumarins. In this research, the extraction of bioactive compounds from sausage fruit with soxhlet extraction process has been studied. The purpose of this experiment is to determine the best type of solvent, solvent to solid ratio, and operating time with varying: type of solvent (methanol and ethanol), volume solvent to weight solid ratio $(8: 1,10: 1,12: 1)$, and operating time (1-3 hours). The experiment found that the optimal extraction conditions were as follows: methanol as the solvent, extraction time 3 hours, and the solvent-solid ratio of $10: 1$ with a yield of $33,12 \%$. The result of a qualitative test of the extract shows that the extract contains flavonoids, iridoids, naphthoquinones, and coumarins. Meanwhile, the result of a quantitative test shows that the extract contains flavonoids as much as $5168 \mathrm{ppm}$.
\end{abstract}

Keywords: Sausage fruit, extraction, flavonoid, iridoid, naphthoquinone 


\section{PENDAHULUAN}

Pohon sosis (Kigelia Africana) merupakan salah satu tumbuhan tropis dan sering digunakan di Nigeria Selatan sebagai obat herbal dalam mengatasi berbagai penyakit seperti malaria, diare, pening, dan retensi plasenta (Gill, 1992). Buahnya memiliki panjang antara 30 $100 \mathrm{~cm}$ dan lebar mencapai $18 \mathrm{~cm}$ dengan berat antara 5-10 kg serta berwarna cokelat keabu-abuan (Joffe, 2003).

Kigelia africana memiliki beberapa sinonim, seperti Bignonia africana, Kigelia spragueana, Kigelia pinnata, Kigelia abyssinica, Kigelia ellioti, Kigelia elliptica, Kigelia impressa, Kigelia aethiopum, dan Kigelia acutifolia (Jackson dan Beckett, 2012). Bagian-bagian dari tumbuhan ini memiliki banyak manfaat, khususnya pada buahnya. Dalam penelitian yang dilakukan oleh Putri mengatakan ekstrak buah sosis dapat dimanfaatkan sebagai bahan aktif tambahan dalam formulasi sabun transparan (Putri, dkk. 2014).

Adapun dalam laporan terbitan 2002 "African Journal of Botany" melaporkan hasil ekstrak kulit batang dan buah sosis dapat digunakan untuk mengatasi infeksi bakteri. Menurut Putri, dkk. (2014) buah sosis memiliki kandungan naphthoquinones, coumarins, iridoids dan flavonoids.

Buah sosis pun mempunyai manfaat lain yaitu sebagai antioksidan, antibakteri, antijamur, antineoplastik, analgesic, anti-inflammatory, antimalaria, antidiarrheal (Saini, dkk., 2009). Namun, sampai sejauh ini antioksidan yang banyak digunakan di masyarakat merupakan antioksidan sintetis. Oleh sebab itu dibutuhkan antioksidan alami agar lebih aman untuk dikonsumsi. Tujuan dari penelitian ini adalah untuk menentukan jenis pelarut, rasio pelarut/bahan baku, waktu operasi, dan persen yield terbaik dalam proses ekstraksi buah sosis.

\section{METODE}

\section{Bahan}

Buah sosis, etanol 96\%, metanol, parafin, aquades, aluminium klorida, natrium hidroksida, asetat anhidrat, asam sulfat pekat, kalium hidroksida, nheksana, etil asetat, natrium nitrit.

\section{Perlakuan dan Percobaan}

Buah sosis diberi perlakuan awal sehingga diperoleh biji buah sosis, dikeringkan menggunakan oven dengan suhu $60^{\circ} \mathrm{C}$ kemudian diblender dan diayak dengan ukuran 18 - 60 mesh. Setelah itu dilakukan proses ekstraksi padat - cair dengan variasi pelarut dan waktu. Variabel berubah dalam penelitian ini adalah jenis pelarut (etanol 96\% dan methanol $96 \%$ rasio volume pelarut dan berat bahan baku (12:1, 10:1, 8:1) dan waktu (1, 2, 3 jam). Percobaan dilakukan dengan metode ekstraksi padat-cair secara soxhlet. Setelah diperoleh ekstrak dengan \% yield terbesar, dilakukan uji kualitatif dengan metode uji fitokimia dan uji kuantitatif senyawa flavonoid dengan metode spektrofotometri UV-VIS.

\section{Analisa Sampel}

Senyawa naftokuinon dapat diidentifikasi dengan penambahan larutan $\mathrm{KOH}$. Berdasarkan hasil yang diperoleh, saat penambahan $\mathrm{KOH}$ ke dalam ekstrak muncul warna kuning yang menandakan bahwa ekstrak mengandung senyawa naftokuinon.

Identifikasi kumarin dilakukan dengan penambahan larutan $\mathrm{NaOH}$. Berdasarkan hasil yang diperoleh, saat 
penambahan larutan $\mathrm{NaOH}$ ke dalam ekstrak muncul warna kuning yang menandakan adanya senyawa kumarin dalam ekstrak tersebut. Kumarin yang direaksikan dengan basa akan membentuk kumarinat larut dalam air.

\section{HASIL DAN PEMBAHASAN}

\section{Pengaruh Waktu Terhadap Perolehan \% Yield}

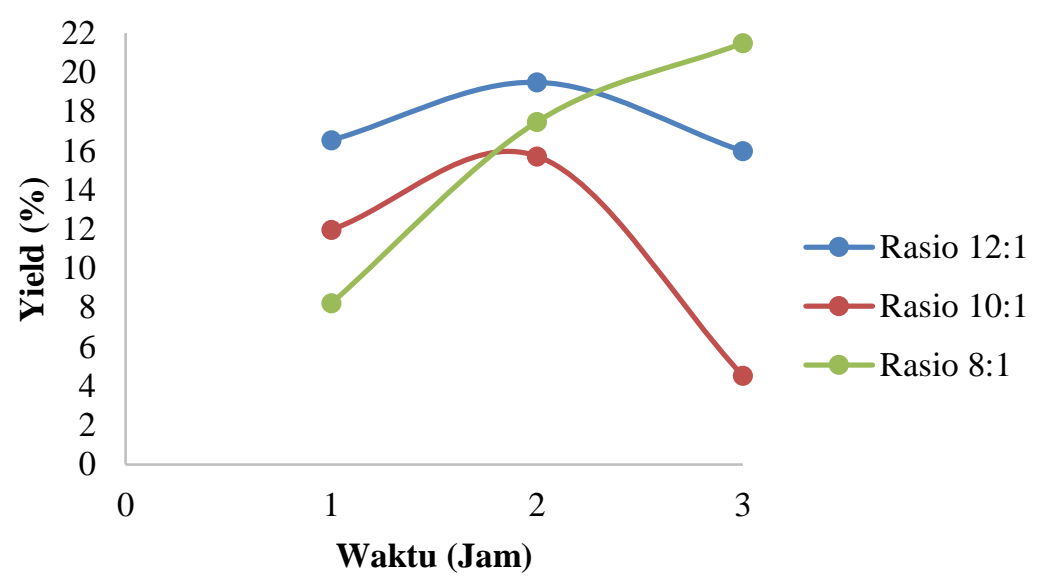

Gambar 1. Pengaruh waktu terhadap \% Yield dengan pelarut etanol 96\%

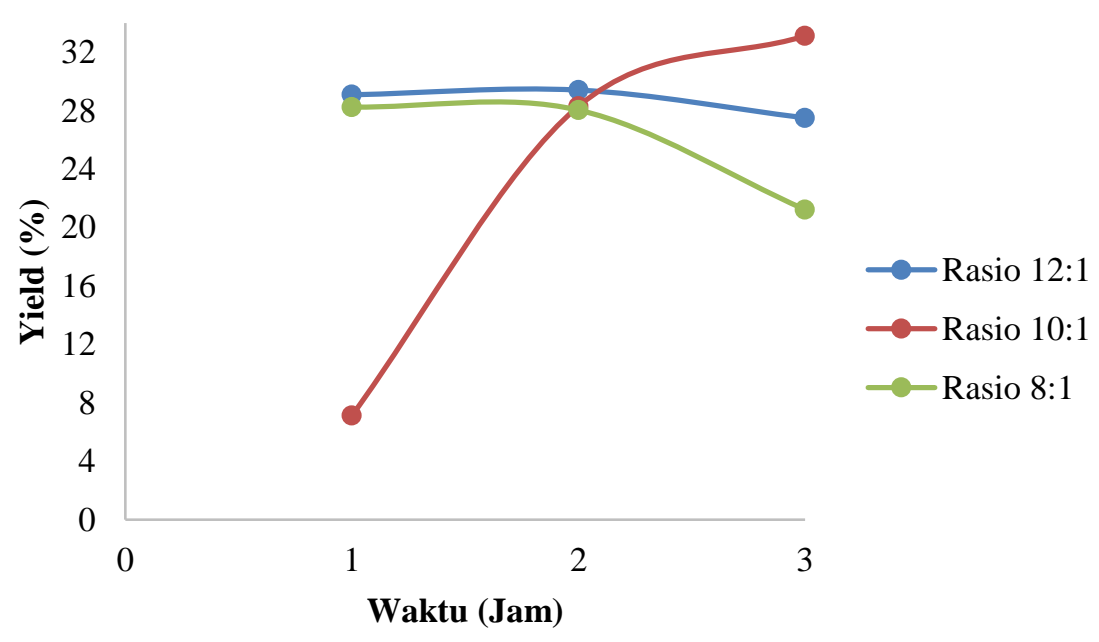

Gambar 2. Pengaruh waktu terhadap \% Yield dengan pelarut metanol

Berdasarkan gambar diatas, diagram yang diperoleh terjadi peningkatan \% yield pada rasio 8:1 untuk pelarut etanol dan rasio 10:1 untuk pelarut metanol seiring dengan lamanya waktu ekstraksi. Hal ini sesuai dengan literatur yang menyatakan bahwa semakin lama waktu ekstraksi, semakin banyak produk yang diperoleh. Namun, hal tersebut tidak terjadi pada variasi rasio 12:1, 10:1 untuk pelarut etanol dan rasio 12:1, 8:1 untuk pelarut metanol karena setiap bahan 
memiliki batas optimum waktu ekstraksi yang mengakibatkan jika waktu telah melebihi batas optimumnya, senyawa yang telah terekstrak dalam pelarut kemungkinan mengalami dekomposisi akibat pemanasan terus berlangsung sehingga produk menjadi berkurang (Shinta dkk., 2008).

Berdasarkan Gambar 1 dan 2, perolehan $\%$ yield dengan pelarut metanol lebih banyak jika dibandingkan dengan pelarut etanol 96\%. Hal ini terjadi karena berdasarkan teori, metanol merupakan pelarut yang mudah masuk kedalam sel melewati dinding sel bahan, sehingga metabolit sekunder yang terdapat dalam sitoplasma akan terlarut dalam pelarut (Lenny, 2006). Hal ini menyebabkan bahan aktif dapat lebih mudah terambil oleh metanol dibandingkan dengan etanol. Maka dari penjelasan tersebut, sampel terbaik pada penelitian ini yaitu variasi metanol dengan rasio pelarut/bahan baku yaitu 10:1, dan waktu ekstraksi selama tiga jam, karena berdasarkan \% yield yang didapatkan yaitu sebesar $33,12 \%$. Untuk membuktikan bahan aktif dalam buah sosis dapat terambil, maka dilakukan uji kualitatif. Dari keseluruhan data yang didapatkan, \% yield yang diperoleh dapat dikatakan sedikit. Hal ini dapat terjadi karena ukuran bahan baku yang terlalu besar yaitu hingga 18 mesh, karena ukuran bahan 20 mesh pun terlalu besar karena dapat menyulitkan pelarut masuk kedalam jaringan bahan dan kontak antara bahan yang diekstrak dengan pelarut menjadi tidak maksimal.

\section{Pengaruh Rasio Pelarut/Bahan Baku Terhadap Perolehan \% Yield}

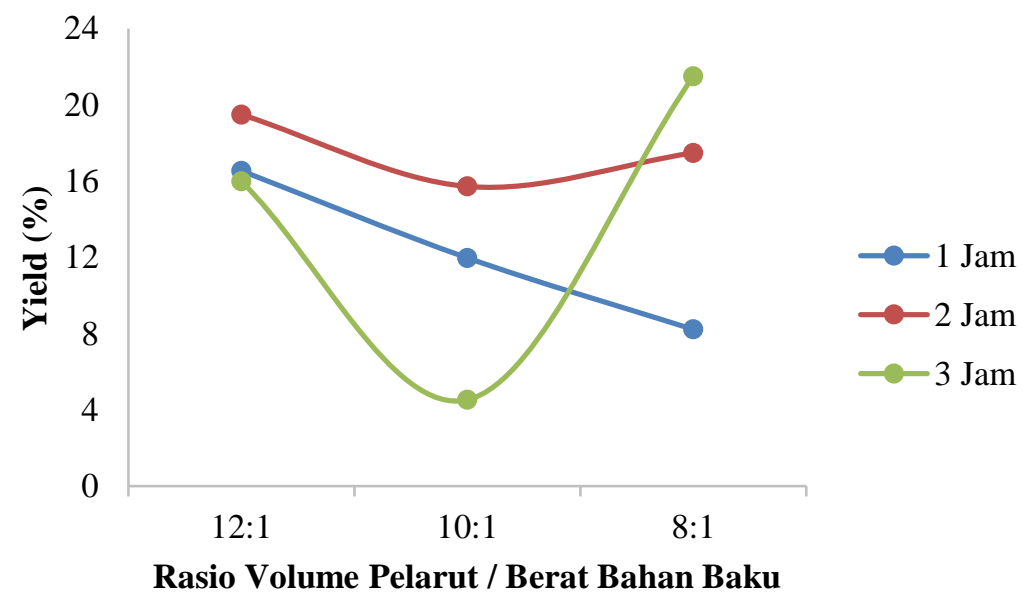

Gambar 3. Pengaruh rasio pelarut / bahan baku terhadap \% Yield dengan pelarut etanol 


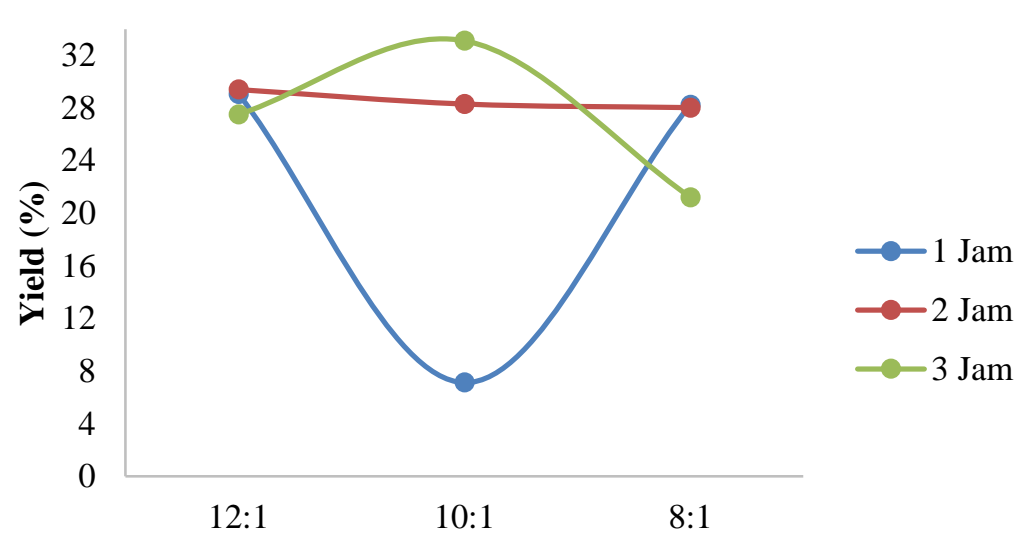

Rasio Volume Pelarut / Berat Bahan Baku

\section{Gambar 4. Pengaruh Rasio Pelarut/Bahan Baku terhadap \% Yield dengan Pelarut Metanol}

Berdasarkan data yang diperoleh, semakin tinggi rasio pelarut/bahan baku, $\%$ yield yang dihasilkan semakin banyak. Hal ini sesuai dengan teori bahwa semakin banyak jumlah pelarut, semakin banyak jumlah produk yang diperoleh, karena distribusi partikel dalam pelarut semakin menyebar, sehingga memperluas kontak (Mardina, 2010). Kondisi tersebut sesuai dengan data yang didapatkan yaitu pada etanol 1 jam dan metanol 2 jam. Adapun untuk variasi etanol 2 jam, metanol 1 jam, dan metanol 3 jam terdapat kecenderungan semakin tinggi rasio pelarut/bahan baku, semakin tinggi juga perolehan \% yield, seperti pada teori yang dijelaskan sebelumnya, namun data naik dan turun secara signifikan pada rasio 10:1. Hal itu dapat terjadi karena pelarut dalam jumlah tertentu dapat bekerja optimal, seperti menurut Wuryantoro rasio bahan dengan pelarut berpengaruh terhadap efisiensi ekstraksi, tetapi jumlah berlebihan tidak akan mengekstrak lebih banyak, dalam jumlah tertentu pelarut dapat bekerja optimal (Wuryantoro, 2013). Berdasarkan gambar 3 dan 4 , untuk variasi etanol 3 jam, didapatkan data fluktuatif, yaitu tertinggi pada variasi $8: 1$, kemudian 12:1, lalu 10:1. Hal ini dapat terjadi karena jumlah tahap yang berbeda-beda, seperti menurut Prasetyo, pelarut dalam jumlah tertentu akan dapat melarutkan bahan secara optimal dengan siklus atau tahap yang telah ditentukan (Prasetyo, 2015).

\section{Hasil Analisis Senyawa Organik}

Hasil uji fitokimia dari ekstrak metanol buah sosis menunjukkan hasil yang sesuai menurut Putri, dkk (2014) yang dilihat dari perubahan warna setelah ditambahkan pereaksi. Warna tersebut muncul karena adanya pembentukan senyawa kompleks antara senyawa yang diinginkan dengan pereaksi yang ditambahkan. Hasil uji fitokimia ditunjukkan pada Tabel 1 . 
Tabel 1. Hasil Uji Fitokimia

\begin{tabular}{llc}
\hline Golongan Senyawa & Warna & Ekstrak Metanol \\
\hline Flavonoid & Kuning & + \\
Kumarin & Kuning & + \\
Naftokuinon & Kuning & + \\
Iridoid & Cincin hijau & + \\
\hline
\end{tabular}

Uji kuantitatif pada ekstrak dilakukan untuk menentukan konsentrasi flavonoid dengan metode spektrofotometri uv-vis dengan panjang sinar yang digunakan yaitu $510 \mathrm{~nm}$.

Berdasarkan uji kuantitatif yang telah dilakukan, diperoleh konsentrasi flavonoid pada ekstrak metanol buah sosis sebesar 5168 ppm. Iridoid merupakan senyawa yang termasuk ke dalam klasifikasi terpenoid. Identifikasi senyawa terpenoid

dalam ekstrak buah sosis dilakukan dengan penambahan larutan asetat anhidrat dan asam sulfat. Asam asetat anhidrat digunakan untuk menyerap air dan membantu pengoksidasian asam oleh asam sulfat. Jika terdapat kandungan air, reaksi pengoksidasian asam tersebut tidak akan berlangsung. Berdasarkan hasil yang diperoleh, ketika ekstrak ditambahkan asam asetat anhidrat dan asam sulfat, muncul cincin berwarna

\section{DAFTAR RUJUKAN}

Gill LS. 1992. Ethnomedical Uses of Plants in Nigeria. Benin City: Uniben Press.

Jackson, Simon dan Katie Beckett. 2012. Sausage Tree Kigelia Pinnata: An Ethnobotanical and Scientific Review. Cms.herbalgram.org diakses pada 23 Januari 2019.

Joffe P. 2003. Kigelia africana (Lam) Benth. Pretoria National Botanical hijau yang artinya terdapat senyawa terpenoid dalam ekstrak. Hal ini disebabkan oleh adanya pembentukan ikatan rangkap terkonjugasi sehingga menimbulkan oksidasi pada senyawa terpenoid.

\section{SIMPULAN}

Berdasarkan percobaan yang telah dilakukan, dapat disimpulkan bahwa variasi terbaik yaitu dengan jenis pelarut metanol, dengan perbandingan rasio pelarut/bahan baku yaitu 10:1, dengan waktu ekstraksi selama tiga jam, dan persen yield yang didapatkan yaitu sebesar 33,12\%. Dalam ekstrak buah sosis terbaik mengandung senyawa aktif yang diinginkan yaitu flavonoid, coumarin, naphthoquinone, dan iridoid. Konsentrasi flavonoid yang didapatkan pada ekstrak metanol buah sosis terbaik sebesar 5168 ppm.

Garden. www.planzafrica.com diakses pada 5 Agustus 2018.

Lenny, S. 2006. Senyawa Flavonoida, Fenil Propanoida dan Alkaloida (Makalah). Fakultas Matematika dan Ilmu Alam. Universitas Sumatera Utara.

Mardina, Primata, Eka N. Astarina, dan Septriani Aquarista. Pengaruh Kecepatan Putar Pengaduk dan Waktu Operasi pada Ekstraksi Tannin dari Mahkota Dewa. Jurnal 
Kimia (Journal of Chemistry), [S.I], nov. 2012. ISSN 2599-2740.

Prasetyo, 20015. Ekstraksi Oleoresin Jahe (Zingiber officinale, Rosc.) dengan Metode Ekstraksi Sokletasi (Kajian Rasio Bahan Dengan Pelarut Dan Jumlah Sirkulasi Ekstraksi Yang Paling Efisien). Malang: Universitas Brawijaya.

Putri, Birgitta Eknis, dkk. 2014. Kadar Polifenol dan Efek Antioksidan Ekstrak Etanol Buah Sosis (Kigelia africana (Linn.) Benth.) Serta Aplikasinya dalam Sabun Transparan. Salatiga: Universitas Kristen Satya Wacana.

Saini, S., Kaur, H., Verma, B., Ripudaman, and Singh, S. K. 2009.
Kigelia africana (Lam.) Benth. - An overview. Natural Product Radiance. 190-197.

Shinta, Endro dan Anjani P. 2008. Pengaruh Konsentrasi Alkohol dan Waktu Ekstraksi terhadap Ekstraksi Tanin dan Natrium Bisulfit dari Kulit Buah Manggis. Makalah Seminar Nasional Soebardjo Brotohardjono. Surabaya. Hal 31-34.

Wuryantoro, H. dan Susanto, W. H. 2013. Penyusunan Standard Operating Procedures Industri Rumah Tangga Pangan Pemanis Alami Instan Sari Stevia (Stevia rebaudia). Jurnal Pangan dan Agroindustri. 2(3): 76-87. 